\title{
Knowledge-Sharing Strategies in Distributed Collaborative Product Development
}

\author{
Sanjay Mathrani ${ }^{1, *}$ and Benjamin Edwards ${ }^{2}$ \\ 1 School of Food and Advanced Technology, Massey University, Auckland 0632, New Zealand \\ 2 Fisher and Paykel Healthcare Limited, Auckland 1741, New Zealand; benjih.edwards@gmail.com \\ * Correspondence: s.mathrani@massey.ac.nz
}

Received: 3 November 2020; Accepted: 7 December 2020; Published: 16 December 2020

\begin{abstract}
Knowledge-sharing strategies are used across the industry as open innovation and distributed collaboration are becoming more popular to achieve technological competencies, faster time-to-market, competitiveness and growth. Sharing of knowledge can provide benefits to manufacturing and new product development (NPD) companies in improving their product quality and enhancing business potential. This paper examines the implementation of knowledge-sharing strategies in New Zealand aimed at bridging the physical locational issues to achieve collaborative benefits in NPD firms through an in-depth case study. The analysis of this only one, but interesting, case extends a holistic multi-mediation model by Pateli and Lioukas for the effect of functional involvement in a distributed collaborative product development environment. This study explores the external and internal knowledge transfer and how it affects early-stage, late-stage, and the overall product development process. Findings present a knowledge-sharing toolset that enhances innovation in all stages of product development overcoming the environmental factors to improve early and late-stage development through a two-way knowledge-transfer loop with distributed stakeholders. An encouraging management culture is found as key for transparent knowledge transfer across cross-functional teams. The organizational structure and management style play an important role for both external and internal distribution of knowledge.
\end{abstract}

Keywords: distributed collaboration; open innovation; knowledge sharing; knowledge transfer; product development

\section{Introduction}

The gathering of knowledge provides benefits that new product development (NPD) companies can use to expand and improve the quality of their products. These collaborations occur between two or more sources of knowledge for enhancing their technological capabilities to achieve competitiveness. New Zealand (NZ) companies often collaborate with knowledge sources in globally distributed geographical locations to gain competitiveness. These dispersed knowledge sources act as hubs where knowledge is shared and transferred achieving faster time-to-market and growth. Such sharing of knowledge instils a challenge between these distributed hubs due to their geographic locations. Knowledge-sharing is a vital activity for exchange of expertise, skills or information between different stakeholders such as people, communities or organizations supported through knowledge management systems [1]. Implementation of knowledge-sharing strategies can be applied in augmenting flow of information and transfer of expert knowledge between sources in different areas of NPD however, how well the integration of knowledge occurs can mitigate risks in these collaborations [2]. New Zealand NPD companies face this challenge often with their numerous suppliers and technical experts spread across multiple geographical locations [3]. 
Knowledge in product development companies can provide a competitive edge, and the implementation of knowledge-sharing strategies is well documented in literature [4-6]. However, use of such strategies in a company with separated geographical locations and their benefits are not clearly defined. Internet-based distribution systems are a standard solution for knowledge-sharing which could be useful when used in NPD companies. However, there is very little or no research that looks into the operationalization of such Internet-based knowledge-sharing platforms and how cross-functional teams could utilize them to maximize their potential benefits across distributed sites [7]. To address this gap, this study investigates how knowledge-sharing strategies are implemented in a distributed collaborative product development environment in New Zealand.

A study by Pateli and Lioukas [8] has investigated the open innovation initiatives of firms in acquiring external knowledge through collaboration and its transformation into innovation outcomes. The study developed a multi-mediation model highlighting the effect of external knowledge transfer on functional involvement in early and late stages of innovation and its impact on innovation performance. This paper uses and extends this model through an investigation into the knowledge-sharing strategies in NZ companies in a distributed collaborative product development environment. The paper examines how NZ companies share knowledge between two geographical locations and how knowledge-sharing strategies are implemented to encourage flow of knowledge.

A case study is conducted in a medium-sized NPD company that operates across 19 zones in New Zealand and 9 regions globally. This study gathers managerial insights from three different functions of the company (product development, sales and manufacturing) to establish how each area implements knowledge-sharing strategies for distributed collaboration. Findings from this study are useful to both academia and practitioners in business to provide key insights of knowledge-sharing strategies in a distributed collaborative product development environment. This paper extends Pateli and Lioukas's framework to identify essential linkages of distributed collaboration, which is a major contribution of this study.

This section has introduced the study. The next section reviews related literature. Section 3 proposes a framework for distributed collaborative product development used in the conduct of this study. The research methodology is explained in Section 4. Section 5 describes the case study. Section 6 presents the findings from different managers in a company setting, with a discussion in Section 7. In this section, a framework based on findings is also developed, which highlights a two-way knowledge flow between distributed stakeholders. The conclusion and future research directions are presented in Sections 8 and 9 respectively.

\section{Related Works}

\subsection{New Product Development}

New product development encompasses the entire process involved in converting an idea or market opportunity into a new product. This approach is becoming the focus of top managements in companies today to provide an edge in the competitive product innovation environment. Handfield, et al. [9] have noted that NPD is also used for the development of new processes or services, which broadens the range of endpoints that are produced in innovation. The pursuit of speed in NPD has become vital to a company's global success in the market [10], with NPD becoming a critical element to the long term welfare of firms [11]. Zaaimuddin, et al. [12] show in their study that components of NPD that affect performance are: innovativeness, market orientation, top management risk-taking, corporate strategic planning, and knowledge-sharing culture. The culture of an organization plays an important role in boosting open innovation dynamics [13]. Company success can depend on a firm's investment into NPD processes, which can rely on integration between different stakeholders and sharing of knowledge between them. 


\subsection{Collaboration}

The power of collaboration can provide success to product development companies through the sharing and combination of knowledge [14], particularly when it follows a few critical criteria. Collaboration is defined by Emden, et al. [15] as a process for cross-organizational linkage. Deck and Strom [16] have emphasized cross-enterprise processes to be a challenge for successful collaboration. Success of NPD collaboration is found both attractive with benefits but challenging with additional risks arising from the association [2]. However, Yan and Luo [17] suggest that specific collaborations with high competitive overlap could have a chance of knowledge overspill. Overall, collaboration is a high reward process that can make product development companies successful if time and effort is taken to ensure the risks are negligible.

Implementing collaboration into NPD can provide benefits of speed to NPD processes, enabling a competitive advantage for global success. However, collaboration could also act as a backward step for companies if communication breaks down. The supplier integration approach in NPD could be viewed as an open collaboration strategy between two companies for speeding up the developmental process [18], which provides benefits in determining agility as a performance indicator for a company's product development success [12]. Bonaccorsi and Lipparini [19] have noted that supplier's knowledge and expertise would help to improve or create new solutions in NPD. However, there is also a chance for the effort and time to go waste, including time spent asking for advice, managing intellectual property (IP), and developing and maintaining trust between the two collaborators [20]. The whole task of involving suppliers in new product development has been summed up by Ağan, Acar and Erdogan [4] to be a delicate arrangement. Collaboration between companies provides opportunities for competitive product development with extra effort and communication to be upheld for successful collaboration. Mathrani, et al. [21] proposed a critical success factor (CSF) framework for collaborative product development shown in Figure 1, which suggests four different contexts (management, team, process and supporting tools) with each having individual constructs that influence the outcome of the process. These constructs are vital in ensuring that an environment of information flow is thriving in cross-functional teams.

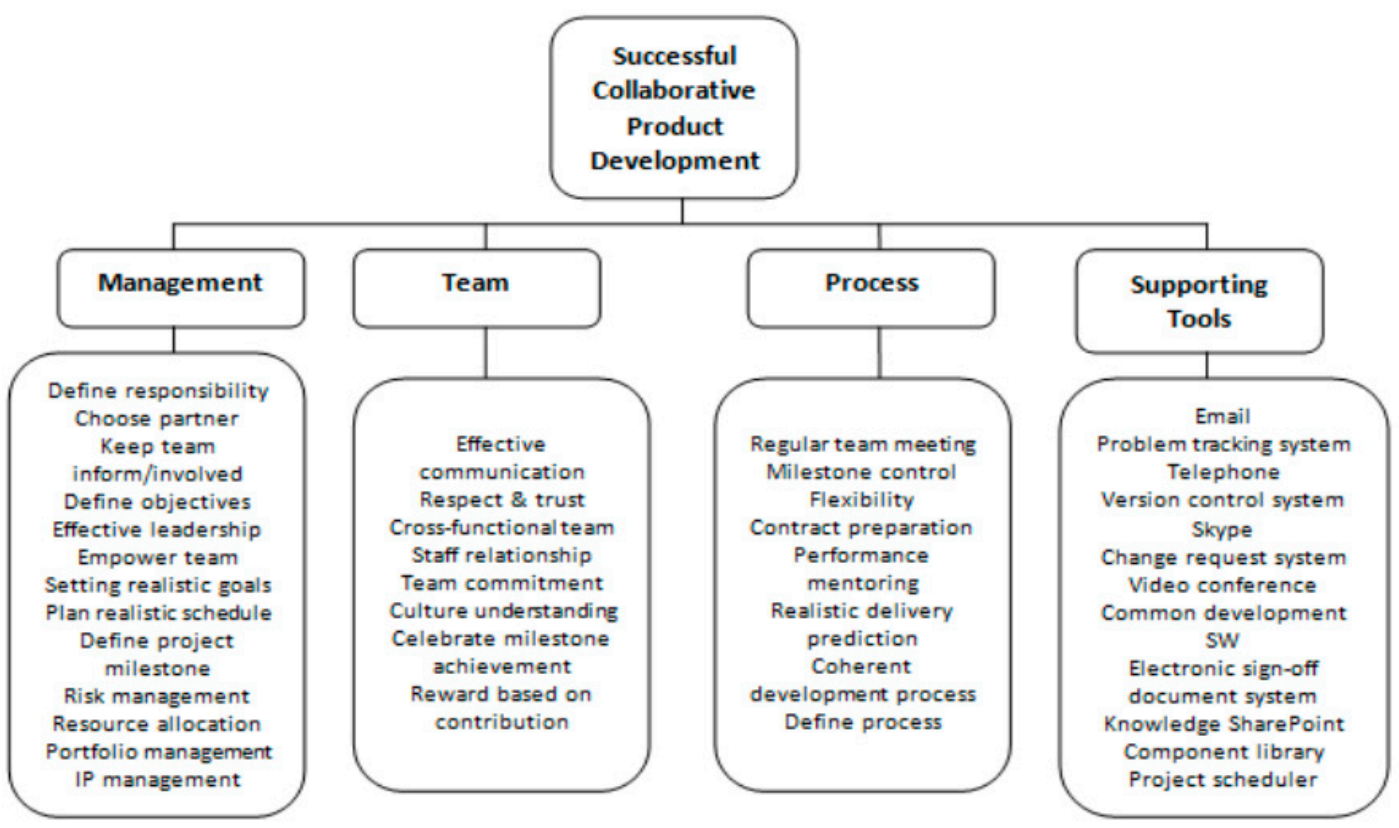

Figure 1. Critical success factors framework (CSF) for collaborative product development, sourced from [21]. 
Collaboration between two distributed physical locations presents more complexities to overcome but can reward companies in having multiple hubs located around the globe. Role-based access is one approach that makes distributed collaboration possible for people with different roles to concurrently work on projects modifying and changing documents/projects [22,23]. Wu, et al. [24] developed a collaborative design environment KMSOLID, which uses RBAC (Role-Based Access Control) and Semantic Norm Model (SNM). This environment allows design collaboration between distributed locations, resulting in global participation from users to produce joint product designs.

Another approach is a remote-collaborative product design system which has a physical facility that connects to other designers locations making a network of physical hubs [7]. Both methods use the Web to connect the different access points, augmenting technical issues that could arise due to the system complexities. The RBAC approach being primarily online would eliminate the physical setup required in other methods, however, Internet-based solutions nonetheless face technical and security risks.

\subsection{Open Social Innovation}

Distributed collaborative product development has antecedents with the open innovation concept in which companies look towards embracing external cooperation for sharing ideas through purposively managed knowledge flows across organizational boundaries in order to advance technology [25].

Chesbrough and Di Minin have defined the role of open innovation in socially inclined firms such as public agencies or nonprofit organizations as open social innovation (OSI) [26]. In this concept, social entrepreneurs apply inbound or outbound open innovation strategies for knowledge flows to overcome social challenges through innovations in the related organizational business models. This is with the understanding that the partners need to align their business models for the alliance to work with identified shared-resources, goals and incentives.

For social entrepreneurs, the open innovation strategies can become more relevant by (i) tapping into the partners resources (ii) having goals that are not merely financial, rather having social objectives is fundamental and (iii) in order to achieve systemic transformation while serving the needs of segments unaddressed by the market, the practices and models implemented must be sustainable socially as well as economically.

Culture is another critical aspect that can play an important role in OSI. The role of culture is explained as an interaction between organizational entrepreneurship of a firm, intrapreneurship of their employees and the entrepreneurship of the new entrepreneur [13]. In accordance to the impetus of each of these sub-entrepreneurship categories, culture could have different attributes such as organizational entrepreneurship leading culture, intrapreneurship leading culture, or entrepreneurship leading culture for open innovation dynamics.

Further, in the current 4 th industrial revolution era, the trends for data exchange and automation in manufacturing technologies have evolved. Several new technological developments such as Internet of things, artificial intelligence, cloud computing, and cyber-physical systems have started to take effect in businesses, value chains, and the entire ecosystem. Organizational sustainability, risk management, innovation and growth rely more than ever before on collaborations via open, dynamic, and flexible platforms.

Recently, a study investigated the micro- and macro-dynamics of open innovation in addition to the dynamic roles of society, university, government, and industry in achieving sustainability in the current 4th industrial revolution era [27]. This study explored how the open platforms are adopted on a continuous basis to develop and maintain an innovative ecosystem. The researchers have proposed a conceptual framework to explain the micro- and macro-dynamics of open innovation through a quadruple-helix model for knowledge, policy, cultural, economic, environmental, and social sustainability.

The findings highlight that the customers and societies have commenced formation of novel concepts for R\&D and commercialization, leading to a shared economy. The universities are now 
actively participating in co-creating knowledge with technology transfer, and the role of the government has moved towards facilitation from regulation control. These transformations lead to further enhancing the development of OSI in the current environment.

A research was recently conducted to analyze the individual social enterprise Burro Battery, and the individual social innovation policy of Grassroots Innovation Festival of India to understand how an OSI could succeed [28]. Findings suggest that the major driver for success is the pursuit of a continuous OSI drive to address social issues with the attainment of benefits in a sustainable manner. Secondly, the policy and agenda for such pursuits must be directly driven by the top leadership with sharing of knowledge between all stakeholders.

\subsection{Knowledge}

Collaboration is not a significant benefit to a product development company unless there is knowledge transfer, therefore, pushing an emphasis on how that knowledge can be shared effectively. Knowledge is the understanding of a subject gained through study, experience, or access to information, which has the potential for influencing future action [29]. Sarvary [30] puts this in another perspective to define knowledge as "information plus the casual links that help to make sense of this information" (p. 11634), simply adding a general approach to the use of information. Therefore, sharing of knowledge and their application has a significant impact on operational, quality and innovation performance [31]. The challenge however being in the implementation of consistent knowledge-sharing strategies to establish a process for dissemination.

The flow of useful knowledge is vital to ensuring its credibility and how it can be understood from the receiving end of the process. With recent technological progressions, knowledge transfer has become efficient and successful. Two main types of knowledge explained in literature are tacit and explicit knowledge. Tacit knowledge is engrained with actions and experience, while including cognitive and technical elements [4,32], e.g., mental models, skills, ingenuity. Explicit knowledge can be symbolic or natural language [29], e.g., user manual of a machine for employees [4].

A well-known model for knowledge creation and transfer called the SECI (SocialisationExternalisation-Combination-Internalisation) has been proposed by Nonaka and Takeuchi [32]. In this model, tacit-to-tacit flow is called socialization (e.g., sympathized knowledge), tacit-to-explicit is externalization (e.g., conceptual knowledge), explicit-to-explicit is combination (e.g., systemic knowledge) and explicit-to-tacit is internalization (e.g., operational knowledge). Therefore, the way these types of knowledge flow to create new knowledge is of importance.

Nonaka and Konno [33] have further emphasized creation of new knowledge through the process of on-going interactions and relationships of individuals with the transfer, sharing and conversion of information. In addition, Asheim, et al. [34] have proposed knowledge bases that incorporate tacit and explicit knowledge known as analytical, synthetic, and symbolic knowledge. Analytical knowledge creates understanding and is explanation-based (know-why), synthetic knowledge is problem-based (know-how), and symbolic knowledge is culture and collaboration-based (know-who).

Comparing these two methods of knowledge-sharing, there is some overlap with regards to the symbolic nature of explicit knowledge and the symbolic knowledgebase that has been described in the study of Ashiem, et al. [34] on sociospatial implications for learning and innovation. These models and functions allow for a breakdown of the knowledge flow between companies, which leads to knowing how these broken-down flows can be integrated in product development company operations. The compounding nature of knowledge is an ongoing process as emphasized by Zammit [35] in their knowledge framework to support a product development team. Their framework comprises four elements - query, identify, capture, and learning-that explain the knowledge cycle of "capturing and sharing knowledge". As this on-going cycle iterates, new knowledge is created in addition to building upon existing knowledge. 


\subsection{Barriers}

Zammit [35] shared a few warnings around the restrictions of knowledge-sharing. People distinguish who and with whom they share information, since a barrier may arise when employees make knowledge-sharing conditional, depending on what information they will receive in return [36]. Introducing personal gain into a person's motive can lead to a negative flow of knowledge and can be negated by the right knowledge-sharing strategies or incentivization.

Although both tacit and explicit forms of knowledge transfer may face complexities, in case of distributed collaborations, tacit knowledge transfer in particular may face several barriers. Rosenkopf and Almeida [37] suggest that the transfer of knowledge becomes harder with a higher geographical distance. A recent study explored the barriers to tacit knowledge-sharing in geographically dispersed project teams in the oil and natural gas industry. The barriers were found to be individual, team, organizational, and external in nature as presented in Table 1.

Table 1. A summary of potential barriers to tacit knowledge-sharing. Adapted from: Olaniran [38].

\begin{tabular}{|c|c|c|}
\hline Theme & $\begin{array}{l}\text { Potential Barriers to Tacit } \\
\text { Knowledge-Sharing }\end{array}$ & Authors \\
\hline Individual & $\begin{array}{l}\text { Little trust, infrequent interaction, } \\
\text { work apathy, individual personality, lack of } \\
\text { knowledge sharing strategies, lack of } \\
\text { reciprocity, and low job skills, lack of time to } \\
\text { share and identify those in need of accurate } \\
\text { knowledge, fear of job security, } \\
\text { poor awareness and evaluation, } \\
\text { and differences in experience levels }\end{array}$ & $\begin{array}{l}\text { Ipe (2003); Ding et al. (2007); Chow and Chan } \\
\text { (2008); Zaglago et al. (2013), Riege (2005) }\end{array}$ \\
\hline Team & $\begin{array}{l}\text { Ineffective use of technologies and tools, } \\
\text { motivations, organizational climate, } \\
\text { communication environment, and cultures } \\
\text { (organizational and ethnic). National culture; } \\
\text { organizational context (organizational culture, } \\
\text { management support, incentives, } \\
\text { and organizational structure); } \\
\text { interpersonal and team characteristics } \\
\text { (team processes, diversity, and social } \\
\text { networks); individual features; } \\
\text { and motivational factors } \\
\text { (knowledge ownership, perceived benefits } \\
\text { and costs, interpersonal trust and justice, } \\
\text { and personal attitudes). }\end{array}$ & $\begin{array}{l}\text { Boer et al. (2002); Hlupic et al. (2002); } \\
\text { Hall (2001); Ardichvili et al. (2003); Hinds and } \\
\text { Pfeffer (2003); Moffett et al. (2003); van den } \\
\text { Hooff and De Ridder (2003), Wang (2010) }\end{array}$ \\
\hline Organizational & $\begin{array}{l}\text { Reduced or lack of organizational knowledge } \\
\text { management strategy, lack of leadership or } \\
\text { managerial commitment that encourages tacit } \\
\text { knowledge sharing, and lack of corporate } \\
\text { culture that supports tacit knowledge sharing, } \\
\text { weak or lack of integration of IT systems and } \\
\text { processes that supports the knowledge } \\
\text { sharing, and lack of staff training on using IT } \\
\text { systems to facilitate the knowledge-sharing. }\end{array}$ & Riege (2005) \\
\hline
\end{tabular}




\subsection{Integration}

Knowledge and the ability to share knowledge can define the success of a company, however, without proper integration and implementation of knowledge strategies, the reward can vary across industries and situations. Davids and Frenken [5] found at different stages of product innovation, certain types of knowledge dominated that stage (analytical in the research stage, synthetic in the development stage, and symbolic in the marketing stage). These findings fell within the framework in Asheim, Coenen and Vang [34], but with some differences in how they explained the discrepancies. Asheim, Coenen and Vang [34] clarified knowledgebase differences between industries, with Davids and Frenken [5] extending the explanation to include differences in knowledgebase across different stages of development in a single project.

Eslami, Lakemond and Brusoni [6] have presented three critical insights around the use of explicit and tacit knowledge in knowledge integration. Firstly, customers of manufacturers can contribute to more than the first stages of development [39,40], being rewarded for collaboration integration and engagement for the full project. Secondly, combination and use of both types of knowledge is imperative. Explicit is useful information for the manufacturer, but the inclusion of tacit allows for further knowledge development through discussion and corroboration. Lastly, the sources of knowledge must be considered, to guide knowledge integration on who knows what [41]. Integration in product development operations can be tricky to implement, but with knowledge frameworks being integrated, can be validated and built upon.

Effective collaboration through distributed geographical locations can enhance core competence, but expose risks, unless governed through a fully functional framework aligned to knowledge-sharing strategies implemented. Davids and Frenken [5] revealed proximity dimensions that supported collaboration innovation and knowledge transfer types in NPD. They emphasized that geographical proximity played an essential role in knowledge transfer through the development and marketing stage with cross-functional teams playing a considerable part in the success of a product development process.

In the literature for open innovation, the "collaborative frameworks" that companies may adopt is a topic of much interest to researchers [42]. These frameworks have focused on two main aspects: the collaboration stakeholders or the stages of collaboration. In the collaboration stakeholders research models within open innovation, several studies have investigated the external players and their relationships with the collaborating company (e.g., [43]). These stakeholders include different organizations ranging from universities, research institutions, market players to competitors, customers, and suppliers (e.g., [44,45]). Some researchers have explicitly emphasized companies to have varied collaboration partnerships (e.g., [46]), with some studies stressing to put focus on collaboration with value chain partners (such as, marketeers, customers, suppliers) (e.g., [47,48]).

In the research focusing on stages of collaboration in open innovation, different models have been proposed (e.g., [49,50]). These models have focused on networking for collaboration or the process approach for integrating knowledge. However, these models do not provide a holistic picture incorporating both, collaboration stakeholders and stages of collaboration, in one process.

Pateli and Lioukas [8] have developed a holistic multi-mediation model which focuses on both collaboration with stakeholders (environmental factors) including market players, research institutions and intermediaries as well as stages of collaboration highlighting the effect of external knowledge transfer on functional involvement in the early and late stages of innovation leading to innovation performance. This framework includes organizational features as factors (e.g., firm size) and environmental effects such as competition, turbulence and patents, which have an impact on the overall performance. One important aspect of this framework is the process of information flow from start to end. The emphasis is on how the external knowledge links with the earlier and later development stages, showing that the external knowledge transfer is critical throughout the process to realize innovation performance. 


\section{Framework for Distributed Collaborative Product Development}

Enthused by Pateli and Lioukas's model, a framework for distributed collaborative product development is proposed (Figure 2) emphasizing the importance of knowledge transfer in a distributed collaborative product development environment. The research framework comprises knowledge transfer from external environmental factors with early-stage and late-stage functional involvement, leading to innovation performance. The major strength of this framework is in its holistic approach to include both, collaboration stakeholders (market players, research institutions and intermediaries) as well as stages of collaboration (early-stage and late-stage functional involvement). This framework also includes organizational features (e.g., firm size) and environmental effects such as competition, turbulence and patents, can only have an impact on the overall performance due to their characteristics, therefore are included in dotted blocks in Figure 2. However, since the original framework lacks in its focus on distributed collaborations, this framework is extended to include knowledge transfer from distributed stakeholders. These distributed stakeholders represent the sources of knowledge through collaboration, which may include knowledge flow represented by an arrow in Figure 2 . Since knowledge transfer could not only be external but also internal, this aspect is also included, allowing the sharing of information gathered in one hub with another through internal collaboration. Thus, external and internal knowledge-sharing in a distributed environment through different stages of functional involvement provides a more holistic representation for realizing innovation performance.

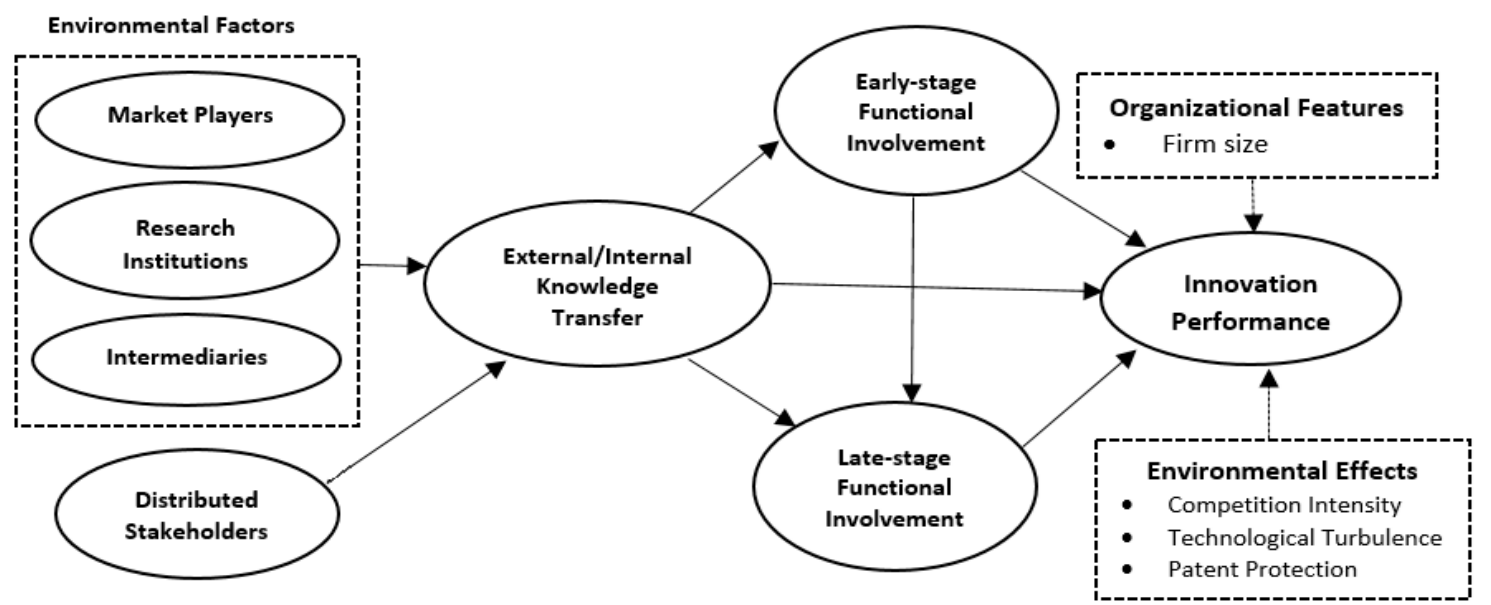

Figure 2. Multi-mediation framework for the effect of functional involvement in distributed collaborative product development, adapted from Pateli and Lioukas [8].

\section{Research Methodology}

\subsection{Research Design}

This paper investigates how distributed collaborative product development companies implement knowledge-sharing strategies in New Zealand.

This research examines the approaches companies use for knowledge-sharing between two or more geographical locations. The measurable for research success in an applied field depends upon how much of the research could be practically used and researchers are recommended to adopt a "reality-oriented qualitative enquiry" [51], p. 94. Therefore, this study uses a qualitative approach [52], through the conduct of a case study in New Zealand to understand the implementation of knowledge-sharing strategies in a distributed collaborative product development environment.

An assumption in the industrial business world is that collaboration stimulates creativity-relevant thinking processes through knowledge-sharing [53]. In this study, this assumption is investigated by evaluating the influence of designers' interactions on innovation performance in a distributed environment using collaborative "thinking experiment" case study. Thinking experiments have been 
used as a case methodology in the development of science, specifically in creative thinking applications through collaborations to create environments that contribute to developing body of knowledge [54]. This research assesses a real-life occurrence in a present-day setting for understanding the complexities of sharing knowledge in a distributed environment and explores how and why questions to make facts understandable. Therefore, case study research is beneficial where a holistic and in-depth evaluation is needed in a broadly complex situation [55].

The epistemology in this study adopts a positivist stance through the semi-structured interviews carried out with research participants for objective and reliable findings. The positivist perspective contends that "reality out there is to be studied, captured, and understood" with respect to theoretical propositions [56], p. 14 assuming that organizational constructs are based upon practices that are "intentional and rational, or at least boundedly rational" [57], p. 60. The ontology assumes that the phenomena's reality is singular, objective, and independent from the researcher. The multi-mediation framework for the effect of functional involvement in distributed collaborative product development, adapted from Pateli and Lioukas (2019) (Figure 2) is used as a methodological and analytical guide in this study to examine how companies implement knowledge-sharing strategies for overall knowledge transfer. Therefore, the positivist thinking experiment case study approach, which is context-dependent from a realist perspective, not only uses the research framework for conduct of study, but also as a methodological approach for capturing the research findings. The results from this research provide new insights in the knowledge-sharing process in a distributed product development setting in a New Zealand context.

\subsection{Case Study Setup}

The case study was based on the following criteria:

- The company is medium to large-sized in the product development and manufacturing industry.

- The company has at least two geographical locations, with one being in New Zealand.

- The company has collaborations with other companies in which the information required around strategies and processes can be revealed under a non-disclosure agreement (NDA) if needed.

- The company has a system network setup to deploy knowledge-sharing strategies between hubs.

- The company develops new products and has current products (or had products) in the market.

- The company can provide time to interview appropriate employees in positions where decisions on strategies can be shared.

If a NZ company achieved this criterion, they were contacted regarding the study and setting up of interviews.

\subsection{Case Study Data Collection}

Once contacted and agreements setup with one medium-sized company (about 100 employees), six semi-structured interviews of about 45 min each were conducted at their main office using a recording device. The participants were the general manager, sales manager, product manager, product development manager, research and development manager and production manager, who are affected by the knowledge-sharing strategies implemented in product development. These are people who design the strategies, make decisions around strategies, implement strategies or work under the strategies implemented. Data were immediately transcribed and analyzed leading to the study results. Questions were asked in relation to the strategies and practices the company deployed for knowledge-sharing in a distributed collaborative product development context. The main objective was to understand the knowledge transfer practices between the company and the distributed stakeholders in different stages of development and how this led to innovation performance. Questions were sectioned into cross-functional team working for knowledge transfer from external agencies (environmental factors), distributed stakeholders, and the internal team members in the early stage and late stage of functional involvement for enhancing technical and commercial knowledge. 
Questions were also asked on the impact of organizational features and environmental effects on innovation performance. These questions followed the format of the theoretical framework (Figure 2). The sections were crafted to gain an understanding on the knowledge-sharing practices in a distributed geographical context placing emphasis on feedback loops that occur during the process. An analytical comparison of the company's strategies against the theoretical framework provided a clear outcome leading to the study results.

\section{Case Study}

\subsection{Company Background}

The case study company is named Alpha (pseudonym). Alpha is a medium-sized New Zealand based ODM (original design and manufacturing) company with about 100 employees. The company has been operating within the outdoor shade industry producing a range of products for over 20 years. Alpha started in Auckland, New Zealand and now sell products through 19 dealerships within New Zealand, and in 9 countries outside of New Zealand. They have grown their product lines, starting from two primary products into a range of outdoor shade products to suit a multitude of features and customer requirements.

\subsection{Case Study Context}

This study aimed to find out the use of knowledge-sharing strategies within companies who are separated by geographical location for collaborative product development. The companies were selected within the New Zealand area based on the accessibility of interviews and the criteria for this study. This research examined how companies have overcome the geographical differences for sharing knowledge to improve product development and presents the study findings.

\section{Findings}

This section presents the empirical findings from Alpha to discuss the knowledge-sharing practices between the company and the distributed stakeholders in both the early and late stages of development and how this led to innovation performance. The format follows the multi-mediation framework adapted from Pateli and Lioukas (Figure 2). First, the internal and external knowledge exchange with environmental factors, internal team members, and external distributed stakeholders is presented. Next, early stage and late stage functional involvement for knowledge exchange are discussed. This is followed by an analytical description of the process outcomes in terms of innovation performance. The last two sections discuss the impact of organizational features and environmental effects in realizing the outcomes.

\subsection{Internal/External Knowledge Transfer}

The knowledge transfer in Alpha is internal as well as from external sources within New Zealand and overseas. Alpha acknowledged the role of environmental factors such as market players, research institutions and intermediaries for providing inputs in areas of product development, technological innovation and market feedback, building a two-way flow of knowledge that improved innovation performance. However, commonly knowledge is transferred at Alpha with exchanges through regular cross-functional team meetings using basic tools such as phone calls and emails. Internal knowledge transfer occurs frequently in the form of face-to-face meetings in which the on-site relevant staff meet and even outside staff are flown into that location to talk in person. Such knowledge transfer can occur weekly or monthly, depending on the stage of development.

The knowledge transfer at Alpha also comes from team meetings in which external sources fly within New Zealand to the head office to discuss and share knowledge internally. The reason for flying external sources to a single location means that they can physically show and discuss design changes and improvements with the entire team, and everyone is completely informed of the decisions 
made with their justifications. These meetings help in establishing decisions with presence of external and internal sources together, which would otherwise not allow adequate clarity challenging the development process. Additionally, the flat structure of the management enables team members to collaborate actively.

The key challenge into external knowledge transfer from sources outside of New Zealand is in flying staff to a location, which is hard due to the high costs and logistics. However, managing external knowledge transfer within Alpha has been successful through phone calls and emails. The primary communication is with manufacturers in different regions around the globe and a set of engineers based in Australia. The feedback to manufacturers is first via emails. "For example, to see if the company can produce an extrusion to the size required. Following this with a phone call to determine precisely what is needed and what design requirements the manufacturer may specifically have." The product manager emphasized "if we can't resolve something within two emails, then we call them". He made evident that working closely with manufacturers throughout the product value chain improved chances of the product not having issues.

Another example stated was when after consulting a previous extruder who were unable to do an extrusion large enough to fulfill the requirements, a suggestion was made to another manufacturer in Australia who could produce something more substantial. After talking to them, the manager spoke to the powder coating firm and the shipping company to see if there were precautions needed for something of that size. Thus, gathering external knowledge from collaborators who specialized in specific operations, allowed them to make changes to the product ahead of those activities, reducing chances of issues arising later.

\subsection{Early-Stage/Late-Stage Involvement}

Alpha has partnered with an Australian manufacturing company where they own the intellectual property (IP) to the product produced within that factory. A lot of product development comes from the engineers of that Australian company. "Early-stage product development was a problem between the head office in New Zealand and the Australian manufacturing unit because the prototyping of initial designs in Australia needed to be tested quickly within the assembly lines in New Zealand. The preliminary-stage feedback on issues faced during the assembly processes in New Zealand led to making changes to the design by the Australian engineers for re-testing. This iterative process was cumbersome due to the geographical distances between the two sites. The head office found a solution by investing in a rapid development $3 \mathrm{D}$ printer, where they could prototype the designs, make changes and test-fit in the assembly line in New Zealand, flying the final prototype to Australia for manufacture. This was a more economical and technically feasible option compared to the earlier process".

Once the primary component left the Australian factory and was installed within the full assembly in New Zealand, further development was needed in the later validation stages for the assembly to work flawlessly. This presented a barrier where they required the skills of Australian engineers to help improve the product in the later development stage while physically being assembled and tested in New Zealand. "Software solutions like remote logins allowed the Australian engineers to login into the component design system in New Zealand to make further changes and improve the product". This way Alpha could overcome the remote design issue with an effective system highlighting the early-stage and late-stage design staff involvement in collaborative development that enabled the transfer of knowledge from overseas engineers to jointly develop the product in the preliminary and final assembly phases.

\subsection{Innovation Performance}

The product innovation in Alpha has shown progress throughout their history, and they are a company that has been growing since their first product line was launched. There was a mix of different viewpoints within managers that allowed for input of varying criticism, however there was 
a consensus in the innovation performance of the company, which was in proportion to the growth advancements made over the years.

The company management participated in the design decisions and ongoing improvements from different areas of the organization which brought in different viewpoints into each product revision. Examples like the views of sales manager were more aesthetically driven while the manufacturing manager would look through the process of making the product. This wide range of views combined with a flat management structure allowing equal input and weighting meant that Alpha could look further down the line of product development when considering design decisions. All three participants found this helpful within the cross-functional team meetings because it challenged the current designs in multiple aspects. They concurred that the products exposed to multiple viewpoints and developed by cross-functional teams produced better results.

Alpha grew from just three people to over fifty in fifteen years with a lot of local and global dealers established for selling their products. This was achieved through both incremental product upgrades as well as more innovative and radical developments over time. Alpha's approach to growth has been slow and steady, taking leaps and allowing factors to settle before moving forward again. An example of this was their acquisition of an intellectual property in Australia, which added a component into their assembly, enabling movable components within their design. "This acquisition was a carefully thought out plan as a strategy for growth. Such step by step actions has allowed the company to grow steadily and branch into markets with a cautious but reassuring plan". Achieving growth is a challenge in larger organizations because monitoring of such progression can become complex. The approach of Alpha CEO was not to aggressively grow the corporate business but have a steady growth which was widely accepted within the company.

\subsection{Organizational Features}

The benefit of being a company within a small country like New Zealand was highlighted with local operations being within the same time zone and the possibility of flying in external sources of knowledge to a common location without a huge cost burden. It was expressed that these in-person meetings only happen once a month, "so that logistic costs could be controlled while still allowing face-to-face knowledge sharing". Two of the participants expressed interest in a Skype like set up, which would allow meetings to occur potentially every fortnight, enabling more frequent improvement suggestions.

A potential issue with Alpha's small enterprise operation was future growth. Expanding operations around New Zealand and globally was a challenge for Alpha due to its distributed nature of product development processes. Strategies such as investing in more conference style setups to allow more distributed hubs to connect and have frequent contact with head office by means other than phone calls or emails were being considered. The product manager expressed this when stating "we could cut down on the couriers of 3D printings to the Australian engineers by showing component renderings via a video style meeting. This would cut out the time delay and costs of couriering products across to Australia".

When participants were queried on what they would like to improve going forward in the knowledge-sharing domain of their company, they all responded having a virtual design platform connecting participants globally for joint development work. They currently outsource their product compliance work to a company few kilometers away from their head office. Participants explained the benefit of being able to share knowledge internally using a dedicated computer-based system such as Product Lifecycle Management integrated with CAD system such as SolidWorks that could help improve the designs from the beginning and throughout the different stages of product development. But they all acknowledged the downside that this would not be able to fully replace the need for a face-to-face meeting with the design and other cross-functional team members. "The amount of knowledge we could share with such as system would benefit the company but would come at a cost, which the company would not be able to take full advantage of due to our small enterprise operation and the value preposition from our product development projects". 


\subsection{Environmental Effects}

The environmental forces including competition intensity, technological turbulence and patent protection has created a scenario for Alpha which challenges the company to stay relevant and focused in pushing out technologically advanced designs. The first was the IP acquisition of a component that allowed their product to have more features and came with the opportunity to sell into a market that appealed to more customers. The acquisition was further pushed by higher levels of competition throughout the business arena in the outdoor shade industry. This increased market presence and influenced Alpha to begin looking for new domains to branch into with a distinguished product mix within the market.

Diversifying into markets within New Zealand was easier than expanding into countries worldwide due to the logistical complexities involved in global supplies, and the established brand Alpha had within the New Zealand market. Alpha's interests towards the United States market was introduced through the development of custom products. Alpha was approached with a specific product requirement, which was consulted with the entire management team before committing. "A custom product is not a common theme in NZ but we saw this as an opportunity to break into overseas market and create a presence".

\section{Discussion}

Alpha's primary strategy for knowledge-sharing were the collaborative mechanisms developed through their management culture. Alpha's open culture allowed knowledge transfer including inputs from external environmental factors such as market players, research institutions and intermediaries to be free, transparent and with a two-way flow at all levels of the company. Their strategy followed many collaboration drivers introduced by Mathrani, Mathrani and Liu [21], however the three main factors identified for knowledge-sharing were cross-functional team culture, management involvement, and use of supporting tools. The diverse range of managers involved in decision making allowed multiple viewpoints throughout the product development process. The development teams were made up with staff from different technical backgrounds enabling cross-functionality of each team member to be diverse. These teams are supported in Alpha through their transparent approach to knowledge-sharing. The culture within the managers and staff essentially holds knowledge-sharing at the core and all the three participants stated how knowledge is freely shared two-way, internally through the various levels of the company, and externally with their different distributed stakeholders that builds up the body of knowledge leading to better innovation performance outcomes. Such sharing of knowledge has also led to creating a strong knowledgebase containing valuable and novel information that could be reused in future developments.

Alpha's use of role-based access control tools is consistent with Ferraiolo, Kuhn and Sandhu's (2007) approach of making distributed collaboration possible for different staff to concurrently work on projects. For example, connecting the engineers in Australia to the head office in NZ. This example shows how Alpha has overcome the geographical barriers to improve early and late-stage product development. Using the principles of RBAC, Alpha found a solution adapting well to the requirement.

The flat management structure within Alpha has created a vast amount of knowledge wealth within the industry with a lot of the knowledge shared as tacit knowledge [4,32]. This knowledge is often exchanged through personal interaction which would suggest why Alpha preferred in-person meetings. The other approach to tacit knowledge-sharing was through phone calls and emails as well as use of rapid development tools such as 3-D printers to expedite the process.

The findings from Alpha were similar to the conclusions of Eslami, Lakemond and Brusoni [6] in which, firstly, customers of the manufacturer could contribute to product development throughout the project. These contributions were evident during product development where multiple manufacturers along the duration of the project were contacted at various stages for advice and improvement solutions. Secondly, both types of knowledge-tacit and explicit—were shared, which was shown through both early-stage and late-stage product development. Explicit knowledge sharing was dominant through 
the early phases when the project scoping was undertaken by manufacturers and the specifics of what they could or could not produce was identified. Tacit knowledge was integrated as improvement suggestions later into the projects. And lastly, the sources of knowledge were carefully considered by Alpha with management specifically referring to those who have experience in that area to share knowledge and gain improvement propositions.

Organizational features such as firm size as well as environmental effects including competition intensity, technological turbulence and patent protection are factors that can have significant importance to knowledge creation in a company with use of specific processes or methods of sharing knowledge as was highlighted in Alpha's case. Another notable aspect in Alpha's case was facilitation by the manufacturer for knowledge transfer. The manufacturer was involved right through the development phase, similar to the findings of Eslami, Lakemond and Brusoni [6] suggesting their engagement throughout the project.

Most of the study findings align with the theoretical framework (Figure 3), highlighting the impact of the environmental factors on the external and internal knowledge transfer throughout the process within the distributed collaborative product development domain. However, two specific modifications are proposed based on findings. First, a two-way feedback loop is included in the adapted model from Pateli and Lioukas [8] between the environmental factors and the external/internal knowledge transfer. This is evident from the extent of two-way communication found in Alpha's case with environmental stakeholders. Second, this study confirms a two-way feedback loop with multiple distributed stakeholders as is evident from Alpha's frequency of collaboration with different manufacturers. Since the knowledge transfer mode is not one-way, but rather a two-way knowledge exchange; this can build up further knowledge leading to an enhanced overall innovation performance. With an understanding gained that distributed stakeholders are replicable to suit a company, as was found in Alpha's case, possibility of more distributed stakeholders is evident, added as a broken line impacting external/internal knowledge transfer. The improved and modified framework is shown in Figure 3.

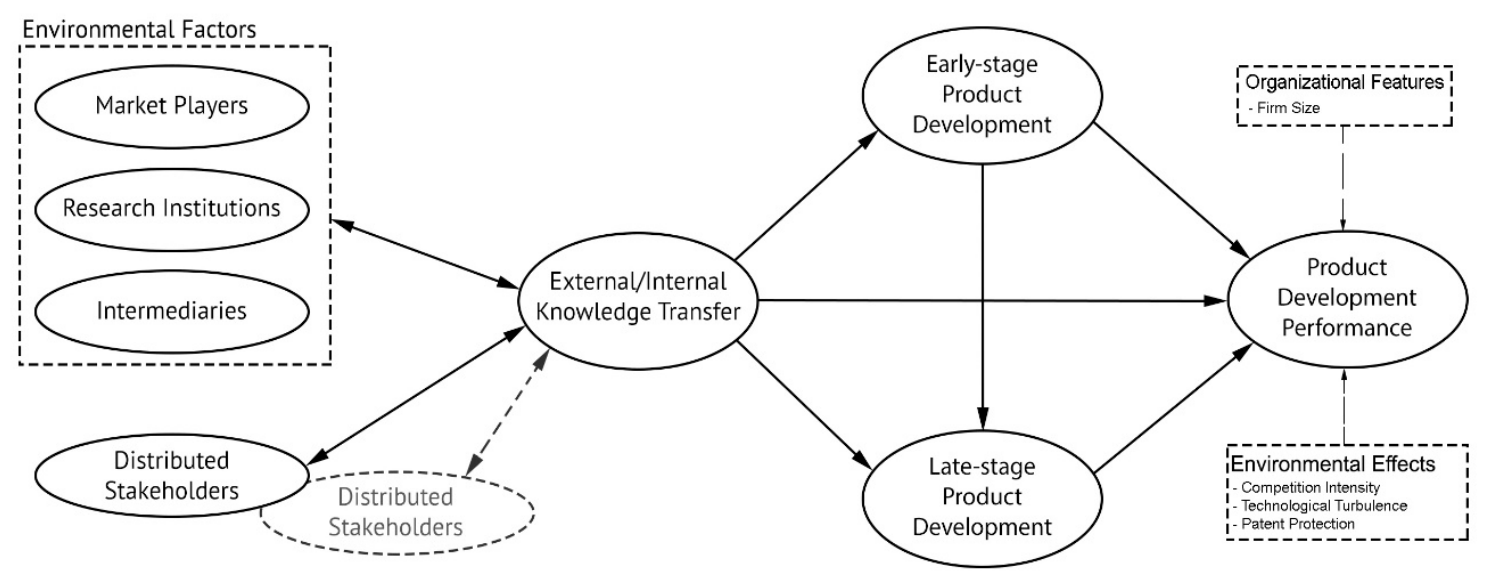

Figure 3. Revised multi-mediation framework for the effect of functional involvement in distributed collaborative product development for future studies.

Alpha has faced several barriers in knowledge transfer due to the geographical distances involved in distributed collaboration. Some of these were: (i) Validation processes requiring inputs from their Australian factory to help improve the product in the later development stage while physically being assembled and tested in New Zealand. This was overcome by using role-based access control tools connecting engineers in Australia to their NZ factory in both early and late-stage product development. (ii) Feedback on issues faced during the assembly processes in NZ led to changes by the Australian engineers for re-testing. This iterative process was cumbersome due to the geographical distances between the two sites. Alpha found a solution by investing in a rapid development 3D printer, 
where they could prototype the designs, make changes and test-fit in the assembly line in NZ, flying the final prototype to Australia for manufacture. This was a more economical and technically feasible option compared to the earlier process. (iii) External sources within NZ could fly down to Alpha's head office for team meetings and sharing knowledge internally, however this was an issue for sources outside of NZ. Further, expanding operations around NZ and globally was a challenge due to the distributed nature of product development processes. Alpha is investing in virtual conference type technological solutions to allow more distributed hubs to connect and have frequent contact with their head office by means other than phone calls or emails. For example, Alpha intends using a dedicated Product Lifecycle Management system integrated with CAD such as SolidWorks that would help improve the designs from the beginning and throughout the different stages of product development. Many of these barriers align with the organizational barriers identified in Table 1 and have been overcome by Alpha using technological solutions.

\section{Conclusions}

The knowledge-sharing strategies at Alpha relied hugely on the culture built within the management to share knowledge, making it transparent and free to access. The supporting tools used were simple but effective in providing links between the geographical distances, evident with use of phone calls, emails, 3-D printers, RBAC systems, and the remote access tools. The multi-mediation framework for the effect of functional involvement in innovation for distributed collaborative product development worked well in establishing a common ground for companies to operate in the knowledge-sharing space. However, the case analysis has determined that the framework by Pateli and Lioukas lacks in providing a two-way feedback loop between the external/internal knowledge transfer with the environmental factors and distributed stakeholders. This study has proposed an extended multi-mediation model (Figure 3) for a two-way knowledge transfer effect in distributed collaborative product development. Overall, the observations of this New Zealand company with worldwide distribution hubs showed valuable knowledge-sharing strategies aimed at bridging the physical locations. Alpha achieved a high level of knowledge transfer throughout cross-functional teams within their development, sales and manufacturing operations using both simple and advanced collaborative tools in their product development processes. The practitioner insights shared in this study would be useful to both academia and industry professionals for future research as well as for formulating knowledge-sharing strategies in distributed collaborative product development environments.

\section{Future Research}

Future research is recommended to compare knowledge-sharing strategies across smaller and larger organizations. Looking at the environmental factors, organizational features and environmental effects in identifying the associated benefits and barriers would be helpful. Another recommendation is to perform more test cases and verify any differences across companies that could improve the modified framework. The current framework has been validated including all aspects of Alpha in this test case. A verification from more companies with a comparison with this study is also recommended in the future.

Author Contributions: Conceptualization, S.M. and B.E.; Methodology, S.M. and B.E.; Software, S.M. and B.E.; Validation, S.M. and B.E.; Formal Analysis, S.M. and B.E.; Investigation, B.E.; Resources, S.M. and B.E.; Data Curation, B.E.; Writing-Original Draft Preparation, B.E.; Writing-Review \& Editing, S.M.; Visualization, S.M. and B.E.; Supervision, S.M.; Project Administration, S.M. All authors have read and agreed to the published version of the manuscript.

Funding: This research received no external funding.

Conflicts of Interest: The authors declare no conflict of interest. 


\section{References}

1. Shaarawy, N. Achieving successful knowledge sharing through enterprise social network collaboration. Bus. Manag. Rev. 2017, 8,1-15.

2. Littler, D.; Leverick, F.; Bruce, M. Factors affecting the process of collaborative product development: A study of UK manufacturers of information and communications technology products. J. Prod. Innov. Manag. Int. Publ. Prod. Dev. Manag. Assoc. 1995, 12, 16-32. [CrossRef]

3. Shekar, A. An empirical study of important dimensions of New Product Development practices in small and medium enterprises in New Zealand. Int. J. Ind. Eng. Theory Appl. Pract. 2011, 18, 83-91.

4. Ağan, Y.; Acar, M.F.; Erdogan, E. Knowledge management, supplier integration, and new product development. Knowl. Manag. Res. Pract. 2018, 16, 105-117. [CrossRef]

5. Davids, M.; Frenken, K. Proximity, knowledge base and the innovation process: Towards an integrated framework. Reg. Stud. 2017, 52, 23-34. [CrossRef]

6. Eslami, M.H.; Lakemond, N.; Brusoni, S. The dynamics of knowledge integration in collaborative product development: Evidence from the capital goods industry. Ind. Mark. Manag. 2018, 75, 146-159. [CrossRef]

7. Bo, L.; Suihuai, Y.; Haijun, W.; Zili, L. Internet-based remote Collaborative Product Design method. In Proceedings of the 2010 International Conference on Artificial Intelligence and Education (ICAIE), Hangzhou, China, 29-30 October 2010; pp. 44-47.

8. Pateli, A.; Lioukas, S. How functional involvement affects the transformation of external knowledge into innovation outcomes. $R$ D Manag. 2019, 49, 224-238. [CrossRef]

9. Handfield, R.B.; Ragatz, G.L.; Petersen, K.J.; Monczka, R.M. Involving suppliers in new product development. Calif. Manag. Rev. 1999, 42, 59-82. [CrossRef]

10. Teece, D.J.; Pisano, G.; Shuen, A. Dynamic capabilities and strategic management. Strateg. Manag. J. 1997, 18, 509-533. [CrossRef]

11. Fliess, S.; Becker, U. Supplier integration-Controlling of co-development processes. Ind. Mark. Manag. 2006, 35, 28-44. [CrossRef]

12. Zaaimuddin, W.A.B.W.; Goh, G.G.G.; Eze, U.C. Knowledge management process and new product development performance in a Malaysian research and development organisation. In Proceedings of the 2009 IEEE International Conference on Industrial Engineering and Engineering Management, Hong Kong, China, 8-11 December 2009; pp. 997-1001.

13. Yun, J.J.; Zhao, X.; Jung, K.; Yigitcanlar, T. The Culture for Open Innovation Dynamics. Sustainability 2020, 12, 5076. [CrossRef]

14. Nelson, R.R.; Winter, S.G. An Evolutionary Theory of Economic Change; Harvard University Press: Cambridge, MA, USA, 1982.

15. Emden, Z.; Calantone, R.J.; Droge, C. Collaborating for New Product Development: Selecting the Partner with Maximum Potential to Create Value. J. Prod. Innov. Manag. 2006, 23, 330-341. [CrossRef]

16. Deck, M.; Strom, M. Model of co-development emerges. Res. Technol. Manag. 2002, 45, 47-53. [CrossRef]

17. Yan, A.; Luo, Y. International Joint Ventures: Theory and Practice: Theory and Practice; Routledge: Abingdon, UK, 2016.

18. Perols, J.; Zimmermann, C.; Kortmann, S. On the relationship between supplier integration and time-to-market. J. Oper. Manag. 2013, 31, 153-167. [CrossRef]

19. Bonaccorsi, A.; Lipparini, A. Strategic partnerships in new product development: An Italian case study. J. Prod. Innov. Manag. 1994, 11, 134-145. [CrossRef]

20. Fidel, P.; Cervera, A.; Schlesinger, W. Customer's role in knowledge management and in the innovation process: Effects on innovation capacity and marketing results. Knowl. Manag. Res. Pract. 2016, 14, 195-203. [CrossRef]

21. Mathrani, S.; Mathrani, A.; Liu, C. Factors that drive success in collaborative product development. In Proceedings of the 1st International Technology Management Conference, San Jose, CA, USA, 27-30 June 2011; pp. 454-461.

22. Ferraiolo, D.F.; Kuhn, D.R. Role based access control. In Proceedings of the 15th National Computer Security Conference, Baltimore, MD, USA, 13-16 October 1992; National Institute of Standards and Technology: Baltimore, MD, USA, 1992; pp. 13-16.

23. Ferraiolo, D.; Kuhn, R.; Sandhu, R. Rbac standard rationale: Comments on a critique of the ansi standard on role-based access control. IEEE Secur. Priv. 2007, 5, 51-53. [CrossRef] 
24. Wu, T.; Pei, X.; Lu, Y.; Chen, C.; Gao, L. A distributed collaborative product design environment based on semantic norm model and role-based access control. J. Netw. Comput. Appl. 2013, 36, 1431-1440. [CrossRef]

25. Chesbrough, H. Open Innovation: The New Imperative for Creating and Profiting from Technology; Harvard Business School Press: Boston, MA, USA, 2003.

26. Chesbrough, H.; Di Minin, A. Open Social Innovation. In New Frontiers in Open Innovation; Chesbrough, H., Vanheverbeke, W., West, J., Eds.; Oxford Scholarship Online: Oxford, UK, 2014. [CrossRef]

27. Yun, J.J.; Liu, Z. Micro- and Macro-Dynamics of Open Innovation with a Quadruple-Helix Model. Sustainability 2019, 11, 3301. [CrossRef]

28. Yun, J.J.; Egbetokun, A.A.; Zhao, X. How Does a Social Open Innovation Succeed? Learning from Burro Battery and Grassroots Innovation Festival of India. Sci. Technol. Soc. 2019, 24, 122-143. [CrossRef]

29. Alavi, M.; Leidner, D.E. Knowledge management and knowledge management systems: Conceptual foundations and research issues. MIS Q. 2001, 25, 107-136. [CrossRef]

30. Sarvary, M. Knowledge management and competition in the consulting industry. Calif. Manag. Rev. 1999, 41, 95-107. [CrossRef]

31. Ahbabi, A.; Singh, S.; Balasubramanian, S.; Gaur, S. Employee perception of impact of knowledge management processes on public sector performance. J. Knowl. Manag. 2019, 23, 351-373. [CrossRef]

32. Nonaka, I.; Takeuchi, H. The Knowledge-Creating Company: How Japanese Companies Create the Dynamics of Innovation; Oxford University Press: Oxford, UK, 1995.

33. Nonaka, I.; Konno, N. The concept of "Ba": Building a foundation for knowledge creation. Calif. Manag. Rev. 1998, 40, 40-54. [CrossRef]

34. Asheim, B.; Coenen, L.; Vang, J. Face-to-face, buzz, and knowledge bases: Sociospatial implications for learning, innovation, and innovation policy. Environ. Plann. C Gov. Policy 2007, 25, 655-670. [CrossRef]

35. Zammit, J.P. A Knowledge Sharing Framework for Improving the Testing Processes in Global Product Development; University of Greenwich: London, UK, 2015.

36. Schmitz, L. Knowledge Sharing: How Do People Share Information in Companies and What Are Communities of Practice? GRIN Verlag: Munich, Germany, 2011.

37. Rosenkopf, L.; Almeida, P. Overcoming local search through alliances and mobility. Manag. Sci. 2003, 49, 751-766. [CrossRef]

38. Olaniran, O.J. Barriers to Tacit Knowledge Sharing in Geographically Dispersed Project Teams in Oil and Gas Projects. Proj. Manag. J. 2017, 48, 41-57. [CrossRef]

39. Blazevic, V.; Lievens, A. Managing innovation through customer coproduced knowledge in electronic services: An exploratory study. J. Acad. Mark. Sci. 2008, 36, 138-151. [CrossRef]

40. Eslami, M.H.; Lakemond, N. Knowledge integration with customers in collaborative product development projects. J. Bus. Ind. Mark. 2016, 31, 889-900. [CrossRef]

41. Schmickl, C.; Kieser, A. How much do specialists have to learn from each other when they jointly develop radical product innovations? Res. Policy 2008, 37, 473-491. [CrossRef]

42. Bigliardi, B.; Ferraro, G.; Filippelli, S.; Galati, F. The past, present and future of open innovation. Eur. J. Innov. Manag. 2020. [CrossRef]

43. Bigliardi, B.; Galati, F. An open innovation model for SMEs. In Researching Open Innovation in SMEs; Frattini, F., Usman, M., Roijakkers, N., Vanhaverbeke, W., Eds.; World Scientific: Singapore, 2018; pp. 71-113.

44. Sieg, J.H.; Wallin, M.W.; Von Krogh, G. Managerial challenges in open innovation: A study of innovation intermediation in the chemical industry. $R$ D Manag. 2010, 40, 281-291. [CrossRef]

45. Spithoven, A.; Clarysse, B.; Knockaert, M. Building absorptive capacity to organise inbound open innovation in traditional industries. Technovation 2010, 30, 130-141. [CrossRef]

46. Dahlander, L.; Gann, D.M. How open is innovation. Res. Policy 2010, 39, 699-709. [CrossRef]

47. Clausen, T.H. External knowledge sourcing from innovation cooperation and the role of absorptive capacity: Empirical evidence from Norway and Sweden. Technol. Anal. Strateg. Manag. 2013, 25, 57-70. [CrossRef]

48. Obal, M.; Lancioni, R.A. Maximizing buyer-supplier relationships in the Digital Era: Concept and research agenda. Ind. Mark. Manag. 2013, 42, 851-854. [CrossRef]

49. Lee, S.; Park, G.; Yoon, B.; Park, J. Open innovation in SMEs-An intermediated network model. Res. Policy 2010, 39, 290-300. [CrossRef]

50. Wallin, M.W.; Von Krogh, G. Organizing for open innovation: Focus on the integration of knowledge. Organ. Dyn. 2010, 39, 145-154. [CrossRef] 
51. Patton, M.Q. Qualitative Evaluation and Research Methods; Sage Publications: Thousand Oaks, CA, USA, 2002.

52. Yin, R.K. Applications of Case Study Research; Sage Publications: Thousand Oaks, CA, USA, 2011.

53. Jonathan, S.; Yan, J. A qualitative study of collaborative stimulation in group design thinking. Des. Sci. 2016, 2. [CrossRef]

54. Tortop, H.S. Why Thought Experiments Should Be Used as an Educational Tool to Develop Problem-Solving Skills and Creativity of the Gifted Students? J. Gifted Educ. Creat. 2016, 3, 35-48.

55. Dube, L.; Pare, G. Rigor in Information Systems Positivist Case Research: Current Practices, Trends and Recommendations. MIS Q. 2003, 27, 597-635. [CrossRef]

56. Denzin, N.K.; Lincoln, Y.S. Strategies of Qualitative Enquiry; Sage Publications Inc.: Thousand Oaks, CA, USA, 2003.

57. Orlikowski, W.J.; Baroudi, J.J. Studying Information Technology in Organizations: Research Approaches and Assumptions. In Qualitative Research in Information Systems; Myers, M.D., Avison, D., Eds.; Sage Publications: London, UK, 2002; pp. 51-77.

Publisher's Note: MDPI stays neutral with regard to jurisdictional claims in published maps and institutional affiliations.

(C) 2020 by the authors. Licensee MDPI, Basel, Switzerland. This article is an open access article distributed under the terms and conditions of the Creative Commons Attribution (CC BY) license (http://creativecommons.org/licenses/by/4.0/). 